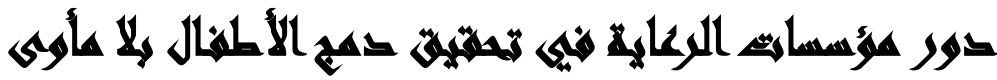

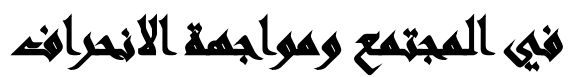

\section{[؛]}

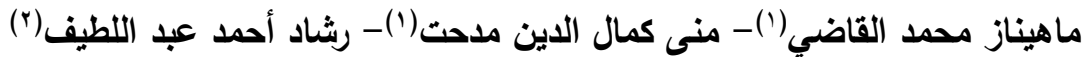

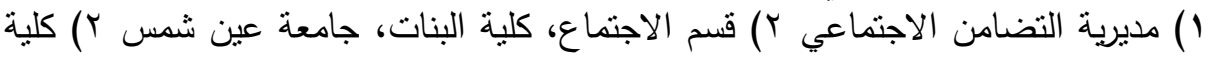
الخدمة الاجتماعية، جامعة حلوان الإنمان

\section{المستخلصع}

يسعى الباحثون من وراء إجراء البحث إلى محاولة تعريف قضية أطفال بلا مأوى بأنها

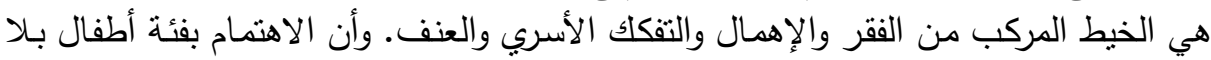

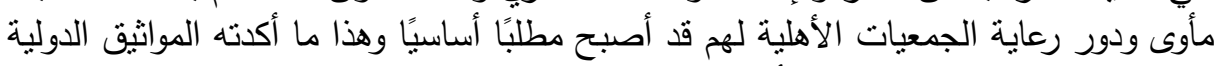

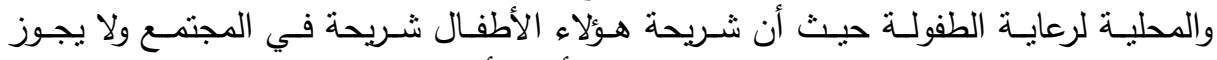

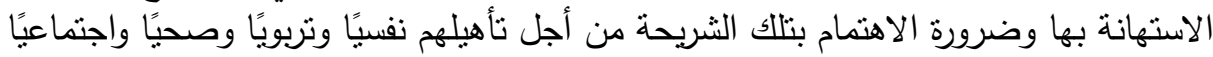

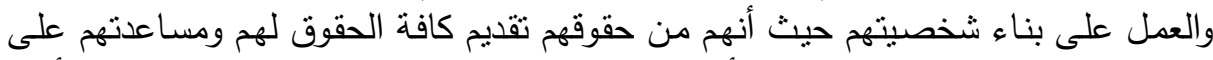

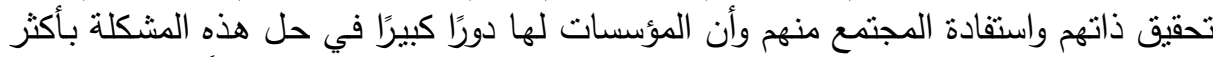

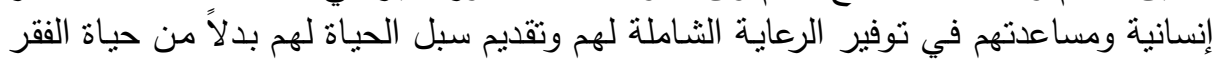
والتثرد التي يعانون منها.

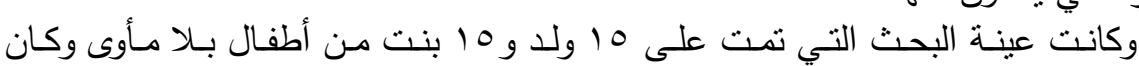

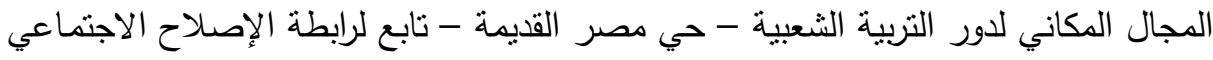

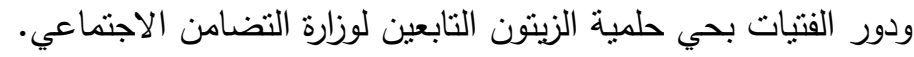

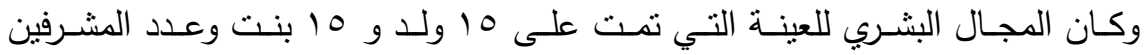

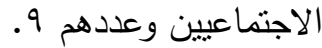

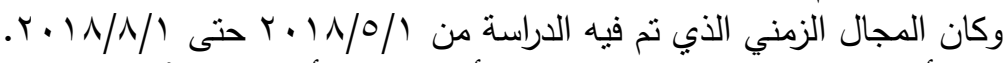

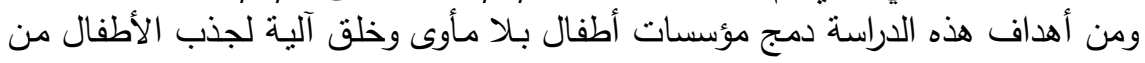

$$
\text { الشوارع نحو الإقامة بدور الرعافه الداية. }
$$

$$
\text { أدوات الدراسة كانت عبارة عن استمارة استبيان. }
$$

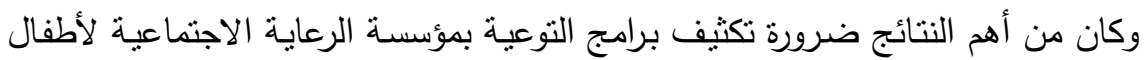

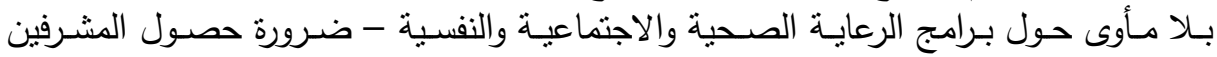
والأخصائيين الاجنماعيين على برامج نوعية ودورات ندريبية. 


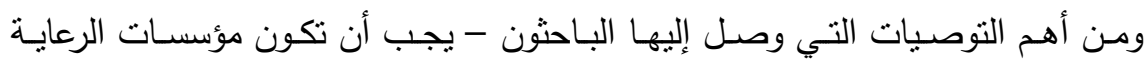

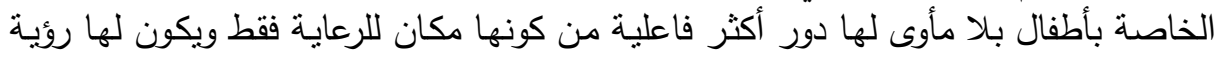

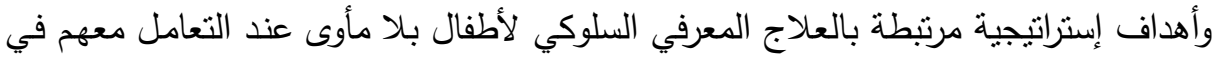
تعديل السلوكيات السلبية لديهر.

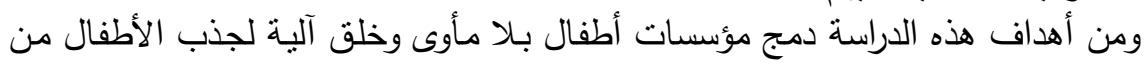
الثوارع نحو الإقامة بدور مؤسسات الرعاية.

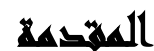

تُعد رعاية الأطفال بلا مأوى من المجالات الإنسانية بالغة الأهمية نظرًا لأنهم يعيشوا

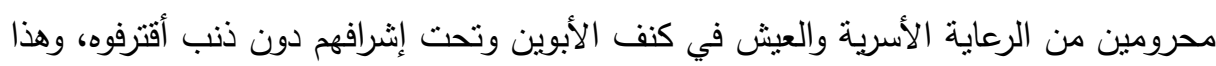
ليس سبب لحرمانهم من الرعاية من طرف مؤسسات الرعاية الاجتماعية بل ينبخي أن يكون

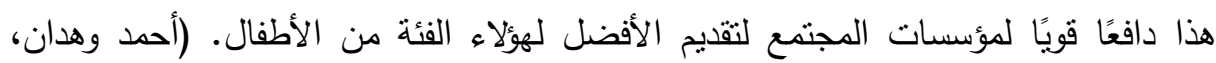
$\left(y^{2} \cdot \mathrm{r}\right.$

إن الأطفال بلا مأوى قد ينعزلوا عن المجتمع ويفقدوا كل الرموز التي كانت حوالهم، وأنهم ليس لهم قيمة ويبدوأ يتسولوا في الثوارع بلا هدف ويعيشوا في عصابات وجماعات.

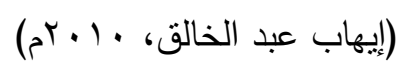

إن مشكلة أطفال بلا مأوى خطر يهدد المجتمع وأمنه واستقراره وهي ليست مشكلة معقدة

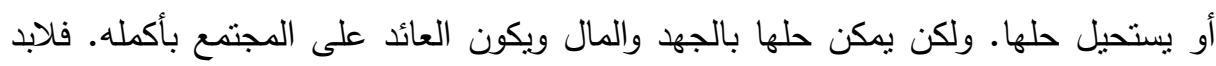

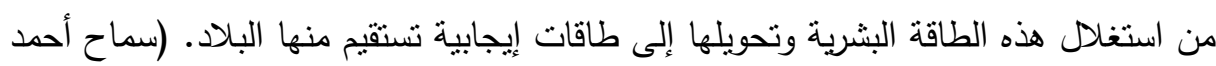

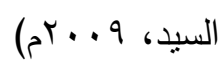

إن مؤسسات الرعاية الاجتماعية تعاني قصورًا في بعض الجوانب الهامة التي تساعد

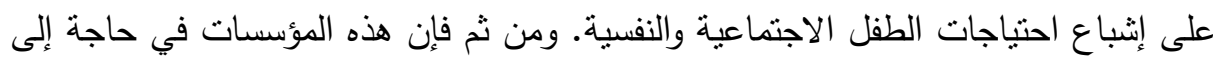

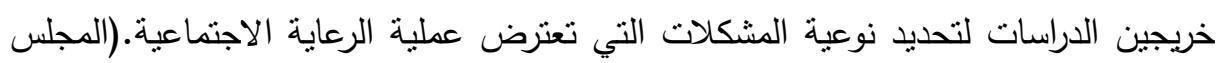

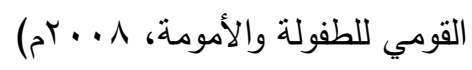




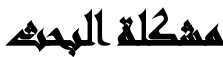

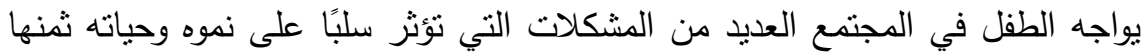

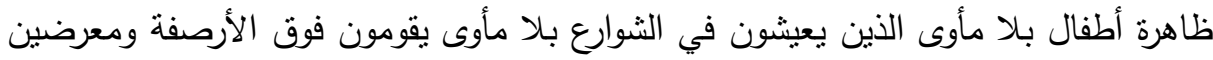

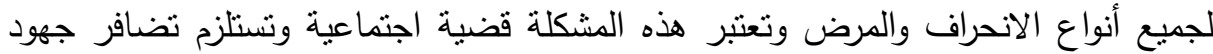

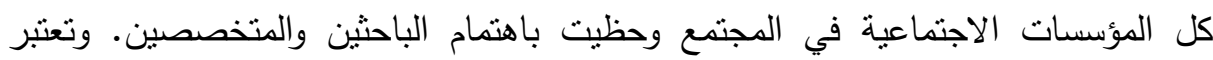
رعاية الطفولة وصون حقوقها مكونًا أساسيًا من مكونات التنمية الاجتماعية التاعية. ومن مظاهر

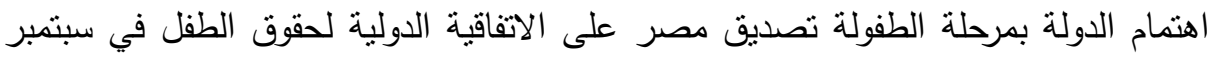

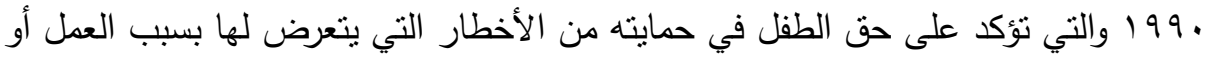

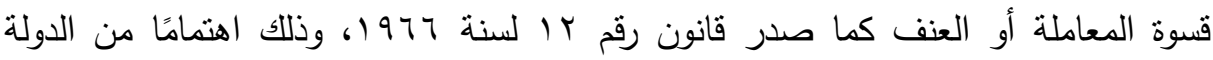

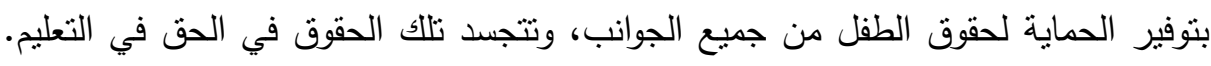

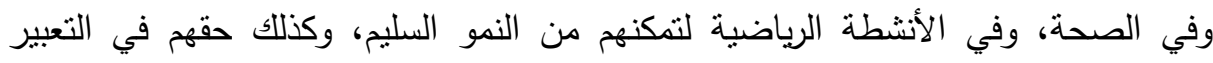

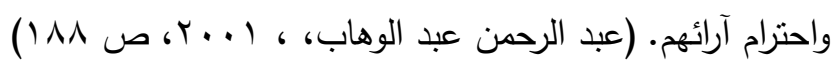

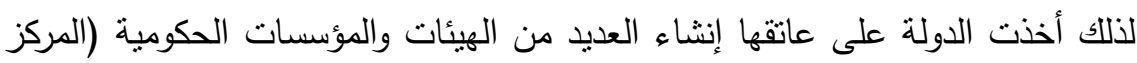

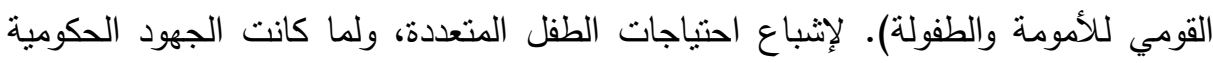

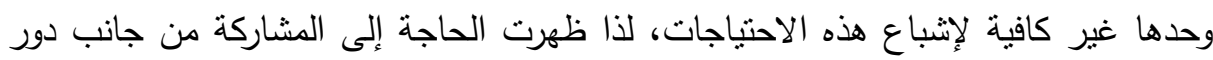

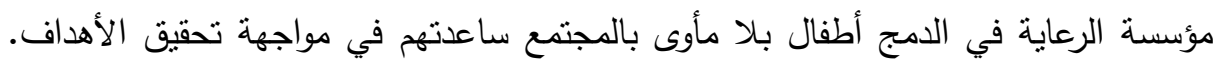

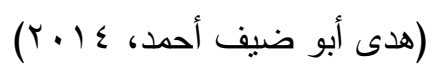

فنجد أن ظاهرة أطفال بلا مأوى تعكس أثنكالاً متعدة للمخاطر الإيجابية التي تهدد أمن

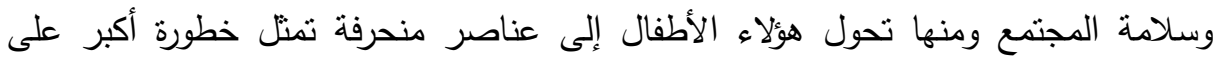

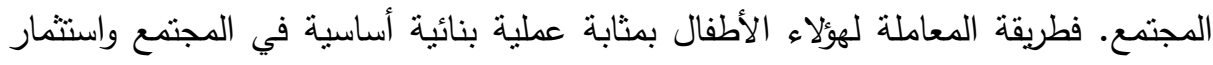

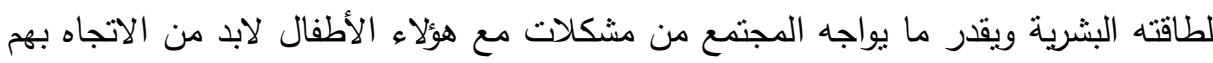

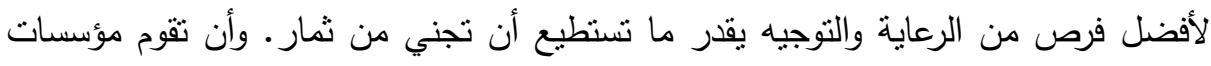

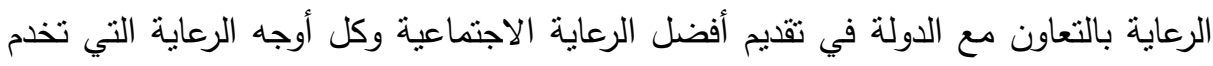
أطفال بلا مأوى وتبعدهم عن الجريمة وتخلق آلية جذب بينهم وبين المجتمع.

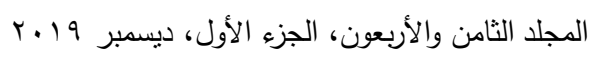


تتشير الدراسات التي أجريت في مجال أطفال بلا مأوى إن تلك الظاهرة تُعد مشكلة فإن

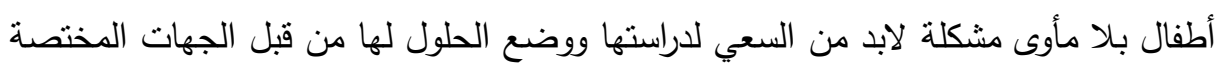

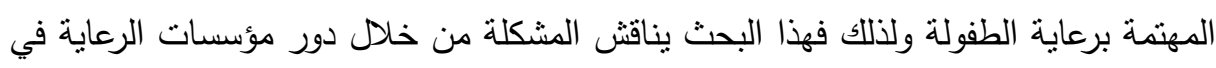

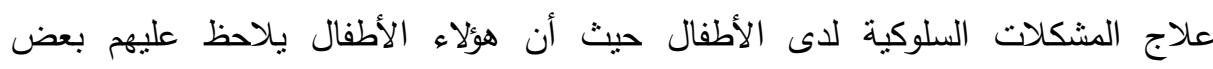
المشكلات منل الكذب والسرقة والعنف.

مشكلة البحث تحاول أن تسعى إلى الإجابة عن السؤال ( ما هو دور مؤسسات الرعاية

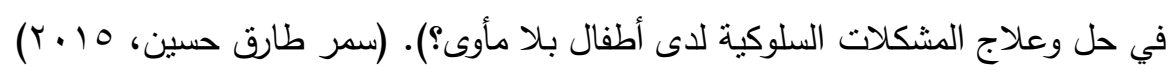

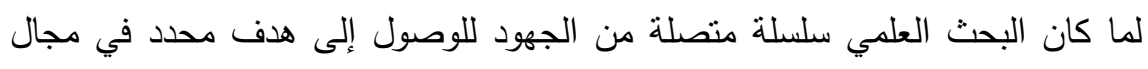

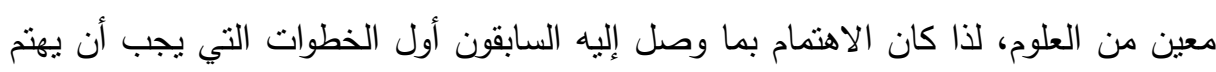

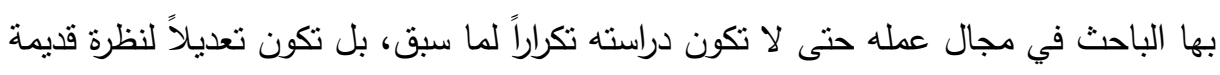
أو إضافة جديدة لم تسبق دراستها، لذا سنخصص هذا الفصل للفي للقيام بمناقشة تحليلية نقدية

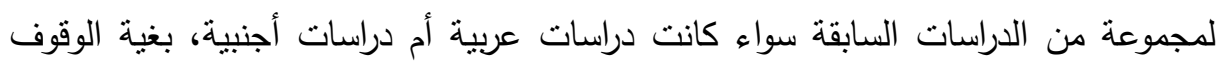

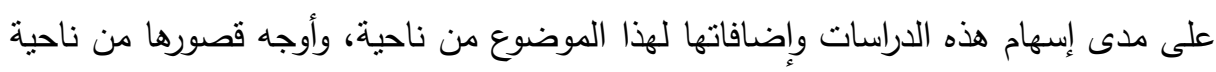
أخرى حتى يمكن أن نحد موضوع دراستتا هذه من بينها، مع ملاحظة أننا في عرضنا وتحليلنا لهذه الدراسات.

\section{أسئلا المهيث}

1-ما نوعية الخدمات التي تقدمها الجمعيات الأهلية في تمكين الأطفال من الحصول على حقوقهم الاجتماعية والنفسية والتعليمية والصحية والاقتصادية؟

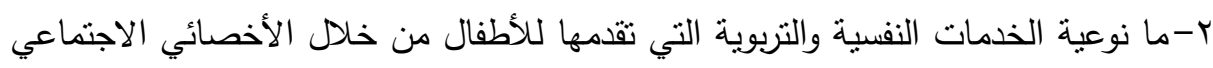
والنفسي بالجمعية ودور الباحثة الاجتماعية للفتيات؟

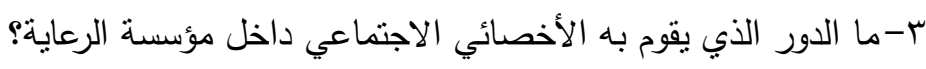

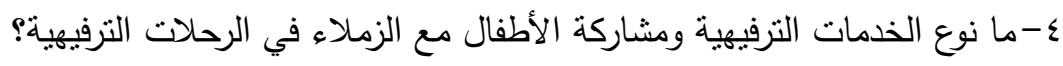

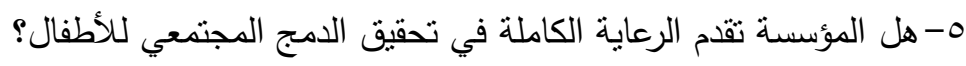




\section{أهمانهم الهمبه}

ا-دور مؤسسات الرعاية في تمكين أطفال بلا مأوى من الحصول على حقوقهم الاجتماعية والتتشئة التعليمية وغيرها.

r-تحديد نوعية البرامج التي تقدما الجمعيات الأهلية في تمكين أطفال بلا مأوى من الحصول على حقوقهم.

r-أن أطفال بلا مأوى فئة ضعيفة اجتماعياً ونفسياً نظراً لظروفهم فهم في أمس الحاجة إلى تقويم الرعاية لهم والمزيد من الخدمات.

ع-تحديد الصعوبات التي تواجه مؤسسات الرعاية في تمكين أطفال بلا مأوى من حصولهم على حقوقهم. ه-دور مؤسسات الرعاية في دمج الأطفال بلا مأوى وخلق آلية لجذب الأطفال من الثوارع نحو الإقامة بدور الرعاية. צ-تقديم مؤسسات الرعاية الاجتماعية الرعاية للأطفال وعمل الدورات لهم لاكتثاف الطاقات والمواهب الكامنة لاى أطفال وتأهيل الموهوبين منهم لإلحاقهم بالأندية المصرية ولتحقيق الديق هذه الأهداف تم صياغة تساؤلات الدراسة.

\section{هزوغر الهمهي}

ا-توجد علاقة ذات دلالة بين الدور الذي تقوم به مؤسسات الرعاية ودمج الأطفال مجتمعيًا.

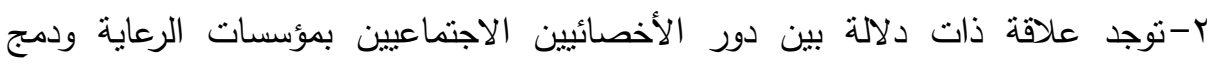
الأطفال في المجتمع الخارجي.

r-توجد علاقة ذات دلالة بين الخدمات التي تقدم للأطفال داخل مؤسسات الرعاية ودمجهر

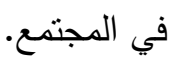
ع-توجد علاقة ذات دلالة بين البرامج والأنشطة التي تقدم للأطفال بلا مأوى بمؤسسات رعاية والتي تناعدهم على دمجهم مجنمعيًا. 


\section{أهمرة المهمه}

تكمن أهمية الدراسة في دراسة المشكلات السلوكية كالكذب والسرقة والعنف وقياس مدى تأثثر البرامج على المؤسسات الاجتماعية وتأثيرها على السلوكيات من حيث كيفية علاجها وهل تكون مؤثرة على سلوكيات الطفل الذي مازال بلا مأوى. ولذا تكمن الأهمية على المستوى النظري: في تقديم الإطار النظري الذي يُقيتم كافة المحاور

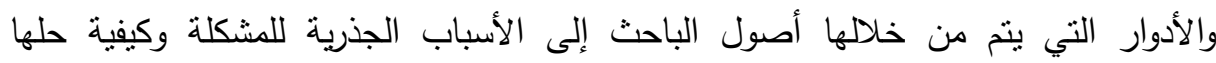
والاستفادة من الدراسات السابقة في حل المشكلة. أما أهمية الدراسة على المستوى التطبيقي: على مستوى الدراسة الميدانية تم التعرف على فلى التئه كيفية الوصول إلى فروق سلوكية بين طفل بلا مأوى داخل المؤسسة والبرامج المقدمة لهم داخل المؤسسة علمًا بأن الدراسة أظهرت أن دور المؤسسة مازال غير فعال في تقديم البرامج السلوكية لهؤلاء الأطفال. من أهمية الدراسة: - الاهتمام المتزايد من الدولة تجاه أطفال بلا مأوى. - - - انتشار ظاهرة أطفال بلا مأوى. - مرحلة الطفولة من المراحل الهامة في حياة الإنسان.

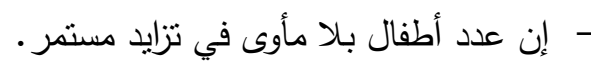
- - مرورة إدماج الأطفال في المجتمع الخارجي.

\section{السواسائ الساريخة}

أثنارت الدراسة السابقة إلى أن هناك مجموعة من المعوقات التي تحول دون إثباع الطفل لاحتياجاته وهي قد تتفق مع الدراسة الحالية على سبيل المثال (نقص الموارد المالية والتي تؤثر على إثباع احتياجات الطفل الاجتماعية والصحية والتعليمية).

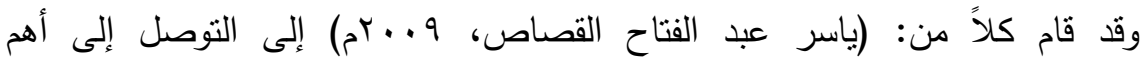

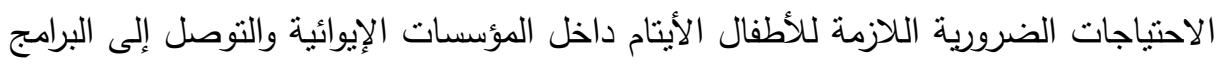
والاحتياجات ومدى إثباعها لأطفال بلا مأوى وكان منهم دراسة الحالة باستخدام الدراسة لإنة 


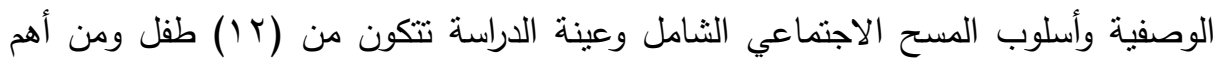

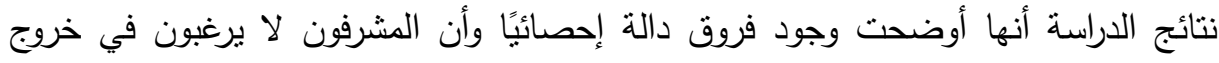
الأبناء من الدار وتكوين علاقات مع الدجتمع الخارجي للحفاظ على أسرار المؤسسة. وأنه يوجد قصور مادي واضحة.

ومن أهم توصيات الدراسة توفير الذدمات اللازمة للتدريب وتوفير الدعم المادي الملائم لتنفيذ برامج وأنثطة البرامج الاجتماعية للمؤسسة. وأكلت الدراسة أن الرعاية داخل المؤسسة دون المستوى المطلوب.

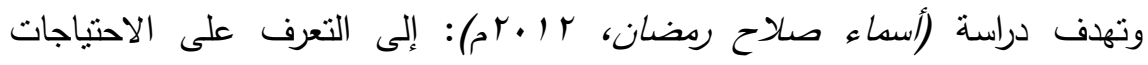

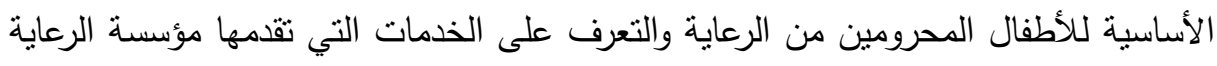

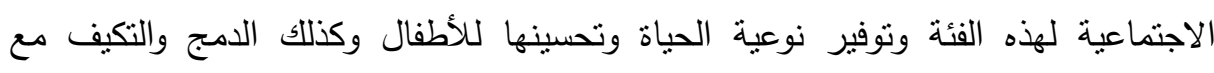

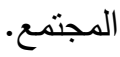
وقد اعتدت هذه الدراسة على نمط الدراسة الوصفية واعتدت على منهج الدسح

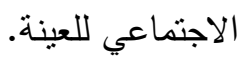
ومن أهم أدوات الدراسة (استمارة استيان) للأطفال بلا مأوى والدحرومين من الرعاية

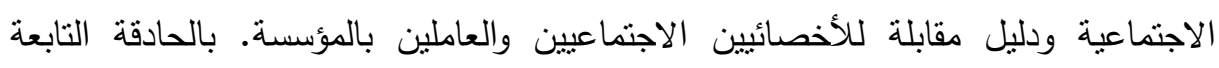
لمحافظة الفيوم، وعدد العينة (10) طفل.

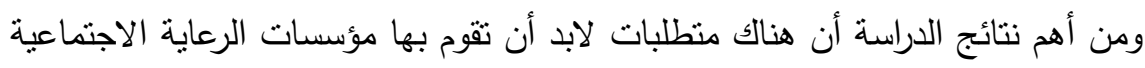

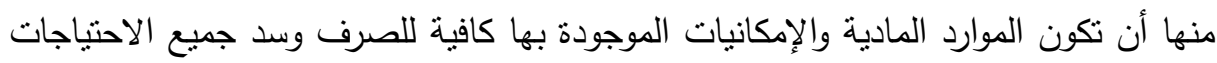

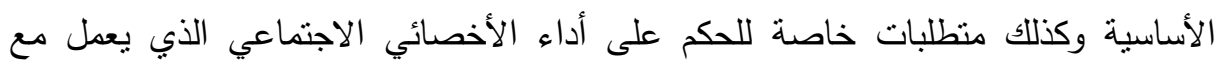

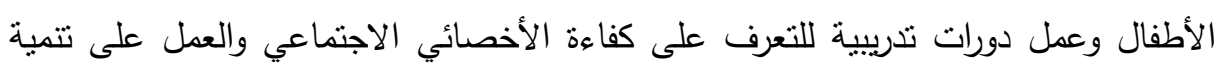


وأثنارت دراسة ( محمود سعد محمود ، با • rم ): أهمية الدور الذي يلعبه الأخصائي

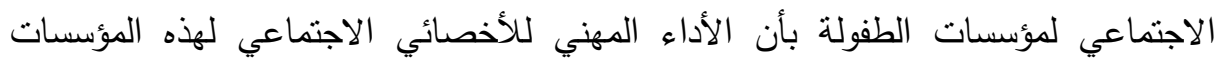

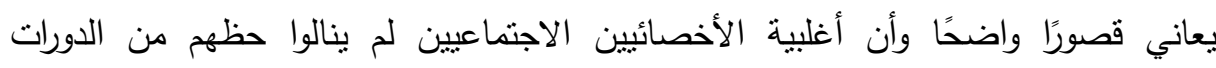
التدريبية.

ومن أهم أهداف الدراسة تحديد أهم المعوقات لأداء الأخصائي الاجتماعي بمؤسسات

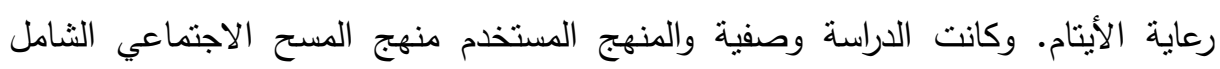
لجميع مؤسسات رعاية الأيتام بمحافظة البحيرة - وكانت أدوات الدراسة (استخدام استمارة استبيان) لجميع الأخصائيين الاجتماعيين والعاملين بمؤسسة الرعاية ولإدارات الاجتماعية بالتضامن.

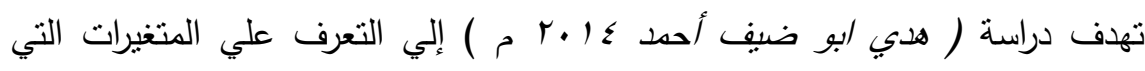

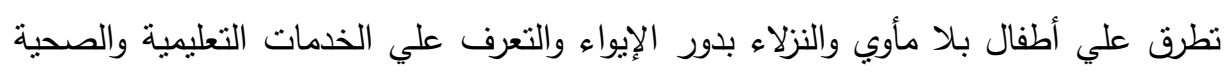
والأجتماعية التي تقدم لهم. وكانت من أهم أدوات الدراسة ( استمارة تحليل الذات - أستمارة الخدمات والأنشطة داخل المؤسسة ) وكانت الدراسة وصفية تحليلية - وكانت الدراسة داخل دور إيواء تبع

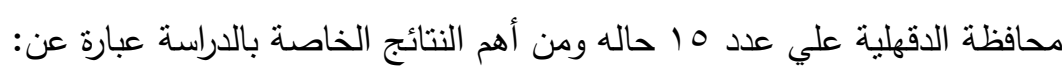

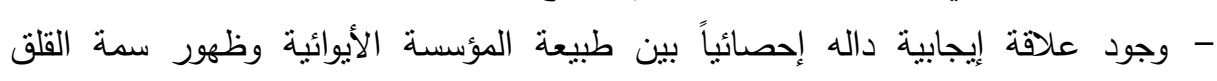
الواضحة علي أطفال بلا مأوي. - وجود علاقة إيجابية داله إحصائياً بين الخدمات التعليمية والصحية والرياضية والترفيهية

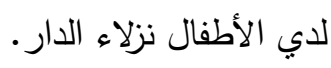

كما أنشارت دراسة (سمر طارق حسين 10 • rم): إلى عدة نساؤلات منها دور المساندة

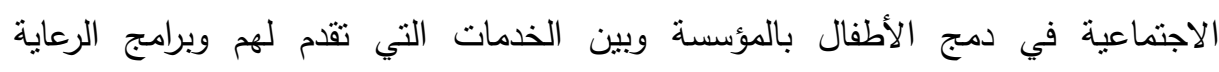
الاجتماعية لضمان جودة الحياة للأطفال المودعين بالمؤسسات الإيوائية والعلاقه بين الموارد المادية وبين الخدمات المقدمه لهم وبين جوده الحياة والمعيشة. وكانت الدراسه وصفيه تحليليه وتتنهج منهج المسح الاجتماعي الثامل لجميع العاملين والمستقيدين بالمؤسسات الإيوائية محل الدراسة وندانه 
ومن أهم النتائج وجود علاقة داله موجبة بين المسانده المالية لدور مؤسسة الرعاية وبين

جوده الحياه داخل المؤسسة.

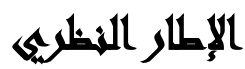

مؤسسات الرعاية الاجتماعية: هي دور إيواء لرعاية الأطفال المحرومين من الرعاية

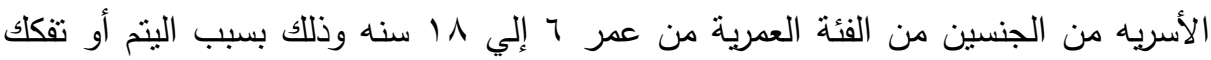

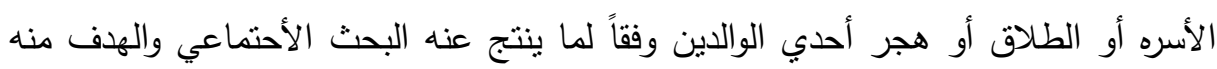
تقديم أوجه الرعاية الأجتماعية والتعليمية والصحية والنفسية والترفيهية لهؤلاء الأطفال. والمؤسسه الإيوائية هي المجتمع الذي يعيش فيه هؤلاء الأطفال مع بعضهم تحت رعاية وائ وائه أخصائيين أجتماعيين ونفسيين متخصصين للتعامل مع الأطفال وكذللك أيضاً من إداريين

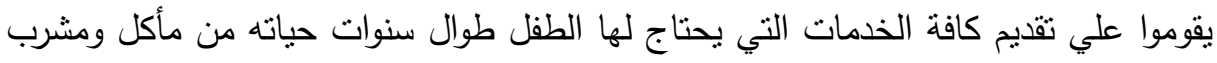

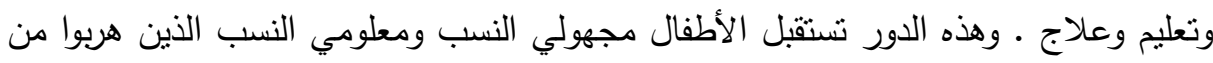

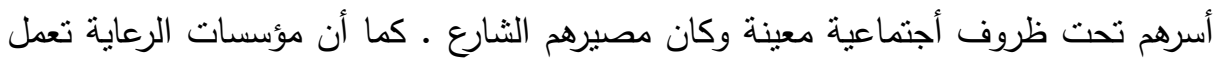

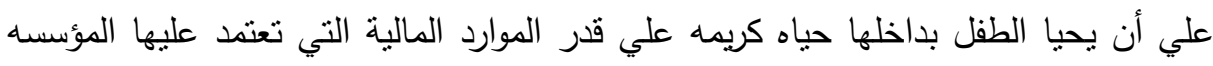

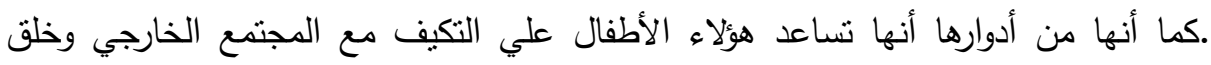

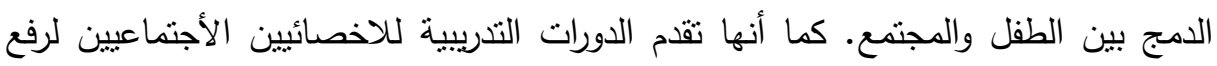

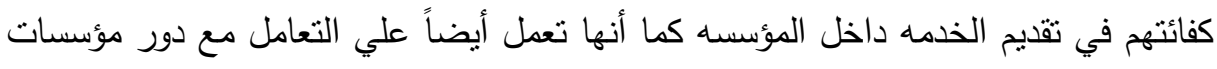
الرعاية الأخري لخلق ألية الجذب بين الأطفال وبعضهم ومن أدوارها أيضاً هي تقديم الحماية

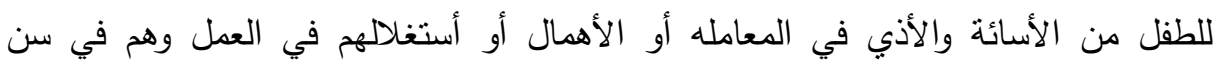

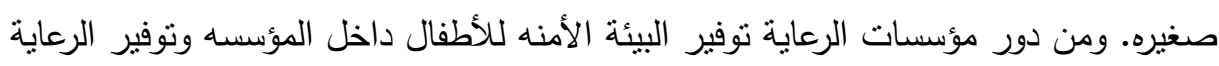
الثنامله لهم وتقديم سبل الحياه لهم بدلاً من حياه الفقر والتترد التي كانوا يعيشونها في الثنارع. أطفال بلا مأوي: هما الأطفال الذين نم تواجدهم بالثارع نتيجة ظروف لهاه أجنماعية معينه

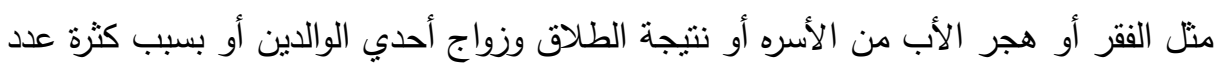

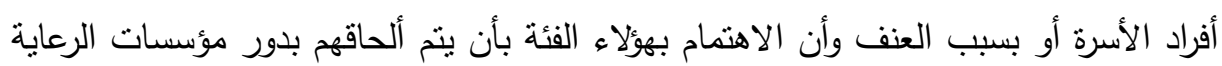


وهذا ما أكدته المواثيق الدولية والمحلية لرعاية الطفولة حيث أن هذه الثريحة من المجتمع لا

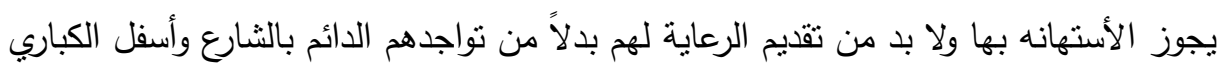

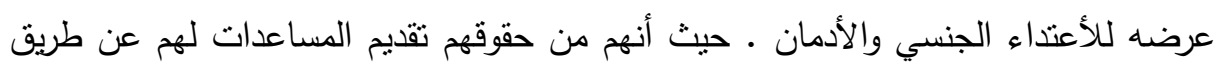

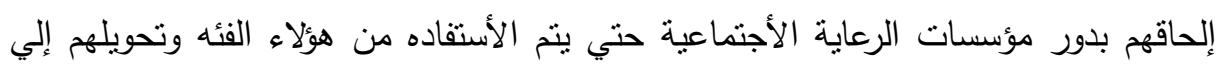

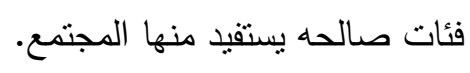

\section{إجباءايت المهيه}

المنهج المستخدم: كانت النظرية المستخدمة هي نظرية الفعل الاجتماعي Social action Theory أطفال بلا مأوي ا- نم اختيار عينة عشوائية في مجتمع الدراسة وعددهم كان (• (7) في المنطقة الجنوبية والثرقية وتم أخذ عينة عشوائية قوامها (·r) طفل وطفلة وقد استغرقت الدراسة شهرين

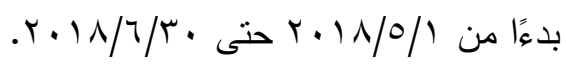

r-في دور التربية الثعبية للبنين حي مصر القديمة ودور رعاية الفتيات بحي حلمية الزيتون.

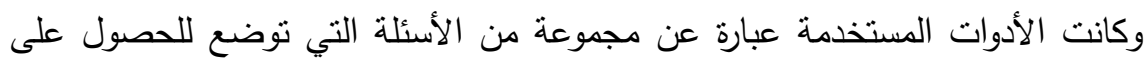
بيانات يجيب عليها الطفل بمفرده أثناء المقابلة. لذا قامت الباحثة بتصميم استمارة استبيان تحتوي على بيانات أساسية وبنود منتوعة على بلى بلى

$$
\begin{aligned}
& \text { النحو النالي: } \\
& \text { - - - بيانات أساسية. } \\
& \text { - - - تاريخ الالتحاق بالمؤسسة. } \\
& \text { - }
\end{aligned}
$$

- قائمة المشكلات السلوكية التي تواجه الطفل داخل المؤسسة مثل:(العنف- السرقة-

- - الرعاية الاجتماعية التي تقدم للأطفال داخل المؤسسة: (رعاية صحية - رعاية ترفيهيةوصف الخصائص لعينة من الأخصائيين الاجتماعيين داخل المؤسسة). 


$$
\text { الأدوات ووصفها: - المات }
$$

- استمارة استبيان لتقييم السلوكيات والبرامج المستخدمة لعلاج الأطفال المقيمين داخل

- بيانات أساسية (الاسم - السن - تاريخ الالتحاق - سبب الالتحاق).

- المستوى التعليمي (حضانة - ابتدائي - إعدادي - ثانوي). - المشكلات السلوكية التي تواجه أطفال بلا مأوى داخل المؤسسة.

- الرعاية الاجتماعية التي تقدم داخل المؤسسة.

- - الرعاية الترفيهية التي تقدم داخل المؤسسة.

- - الرعاية التعليمية التي تقدم داخل المؤسسة.

- - الرعاية الصحية التي تقدم داخل المؤسسة.

وهذا تم داخل دور التربية الثعبية بحي مصر القديمة للبنين.

وداخل دار رعاية الفتيات بحي حلمية الزيتون.

وكانت العينه عبارة عن: عينة على مجموعة من الأطفال في دور مؤسسات الرعاية وكان

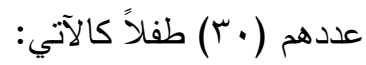

تم أخذ عينة على (10) فتاة في دور رعاية البنات بمصر الجديدة و (10) ولد في دور رعاية التربية الثعبية بمصر القديمة وكانت أعمارهم من (T سنوات حتي 10 سنه ) وكانت

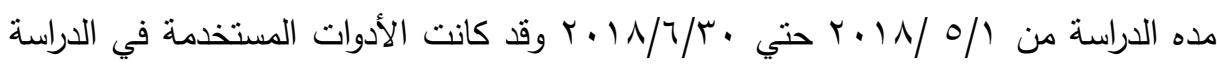

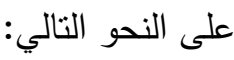

أولاً: الملاحظة Observation: وهي المراقبة والمشاهدة الدقيقة لسلوك ما أو ظاهرة معينة في ظل ظروف معينة وعوامل معيشية بغرض الحصول على معلومات دقيقة في تشخيص هذا السلوك أو هذه الظاهرة.

خطوات إجراء الملاحظة:

- تحديد الهدف الذي يسعى إليه الباحث في الحصول عليه. - تحديد الأثخاص المعنيين بالملاحظة. 
- - تحديد الفترة الزمانية والمكان. - أهمية الملاحظة: -

- الملاحظة أكثر عمقًا من استخدام الأدوات الأخرى تؤمن للباحث معلومات دقيقة.

- - تسجيل المعلومات وقت حدوثها.

ثانيًا: المقابلة Meeting وهي محادثة أو حوار موجه بين الباحث من جهة مع أثخاص

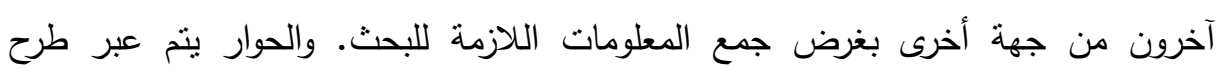
مجموعة من الأسئلة من الباحث التي تتطلب الإجابة عليها من الأشخاص المعنيين (أطفال بلا مأوى). أنواع المقابلة التي تمث: كانت المقابلة شخصية وجهًا لوجه بين الباحث والأطفال المعنيين بالبحث.

خطوات إجراء المقابلة: - تحديد الهدف. - تحديد مكان المقابلة وكان المكان (دور مؤسسات الرعاية). - - - أن تكون المقابلة على انفراد.

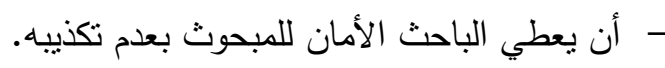

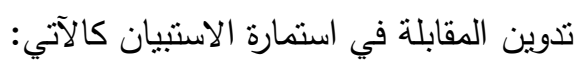
- - بيانات أساسية (الاسم والسن وتاريخ الالتحاق بالمؤسسة وسبب الالتحاق بالنان بالمؤسسة). - المستوى التعليمي (حضانة - ابتدائي - إعدادي - ثانوي). - المشكلات السلوكية التي تواجه أطفال بلا مأوى داخل المؤسسة. - الرعاية الاجتماعية التي تقدم داخل المؤسسة. - - الرعاية الترفيهية داخل المؤسسة. - - الرعاية التعليمية التي تقدم داخل المؤسسة. - - الرعاية الصحية الني تقدم داخل المؤسسة. 
المعالجة الإحصائية: قامت الباحثة بإجراء المعالجات الإحصائية بإجراء المعالجات

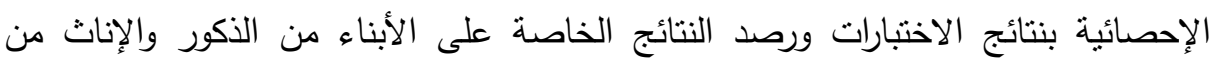

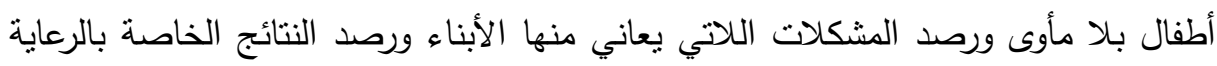

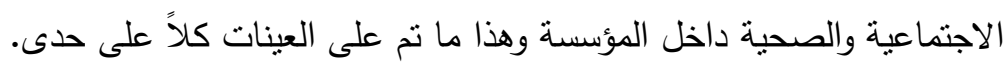

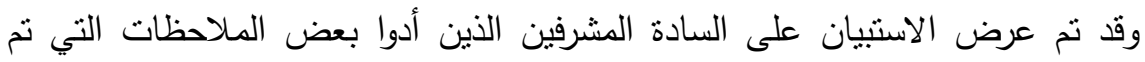
إجراؤها بعد ذلك، ثم إجراء الصدق الظاهري للأداة من خلاد تحكيمها.

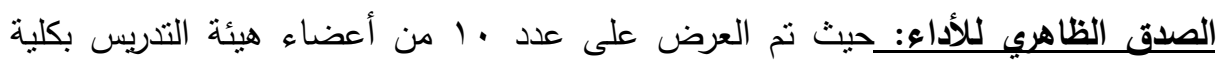
البنات - جامعة عين شمس من لهم خبرة في هذا المجال وبناء على ذللك تم صياغة الاستمارة

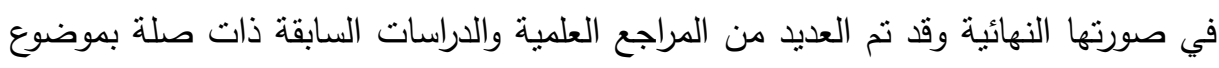
الدراسة لتصميم أدوات الدراسة مع الالتزام بخطوات المنهج العلمي وأصول تصميم الاستمارة من حيث: التراسه 1- أن تكون لغة الأسئلة متمشية مع ثقافة المبحوثين وألا تكون الأسئلة موحية بإجابات معينة والترتيب المنطقي للأسئلة داخل الاستمارة.

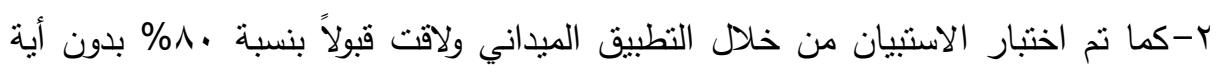
صعوبات وأصبحت الاستمارة في صورتها النهائية للتطبيق. وكانت العينة على (•r) طفل وطفلة 10 ولد بدار إيواء من دار إيواء التربية الثعبية بحي مصر القديمة و 10 بنت بدار إيواء بدور رعاية الفنتات بحي حلمية الزيتون.

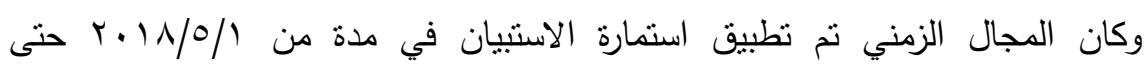
$. r \cdot 11 / 1 / 1$ وكان المجال المكاني في دور التربية الثعبية للبنين بحي مصر القديمة (غرب القاهرة) ودور رعاية الفتيات بحي حلمية الزينون (شرق القاهرة).

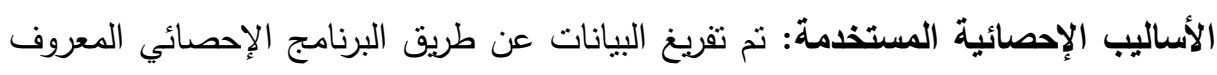

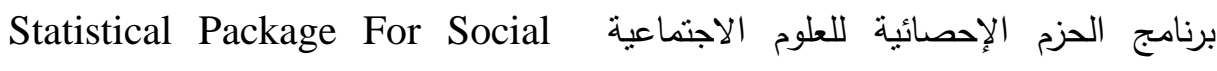
ونم التحليل الإحصائي باستخدام الحاسب الآلي من خلادل برنامج الحزم 
الإحصائية SPSS V. 25 وتعد هذه الخطوة - تفريخ البيانات - خطوة تمهيدية لتبويب البيانات وتحليلها إحصائيًا، ومن خلالهه تم:

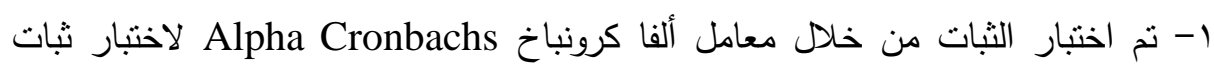

$$
\text { الاستبيان. }
$$

$$
\text { r- المتوسط الحسابي والانحراف المعياري. }
$$

r- اختبار كا` لتوضيح الفروق بين عينة الدراسة.

ع- الإحصاءات الوصفية للبيانات من خلال جدولة البيانات في صورة جداول التكرار والنسب لتبن

$$
\text { المئوية. }
$$

\begin{tabular}{|c|c|}
\hline معامل ثنبات آلفا & آبعاد الاستبيان \\
\hline$\cdot, v \leqslant r$ & إجمالى الاستبيان \\
\hline
\end{tabular}

تبات العبارات لأبعاد الاستبيان

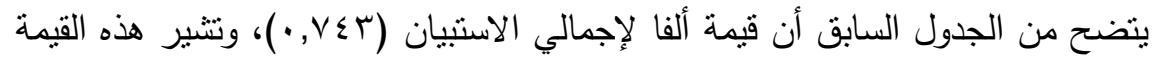

من معامل الثبات إلى صلاحية الاستبيان للنطبيق وإمكانية الاعتماد على نتائجه والوثوق بها.

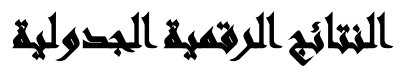

\begin{tabular}{|c|c|c|c|c|c|c|c|c|}
\hline & & & & & & & \\
\hline \multirow[t]{2}{*}{ كا' } & \multicolumn{2}{|c|}{ الإجمالي } & \multicolumn{2}{|c|}{ الناثة دار رعاية } & \multicolumn{2}{|c|}{ التربية الثعبية } & & r \\
\hline & $\%$ & العدد & $\%$ & العدد & $\%$ & العدد & & \\
\hline \multirow{3}{*}{$* \vee, \vee \backslash 9$} & $\overline{r \cdot, \cdot}$ & $\overline{77}$ & $\overline{\mu r, r}$ & $\overline{11}$ & $17, V$ & $\overline{0}$ & آقل 1- ، 1 سنوات & $\overline{\bar{T}}$ \\
\hline & $\pi \mu, \mu$ & 19 & $\mu \cdot, \cdot$ & 9 & r & 1. & ما بين ·1-10 سنة & T \\
\hline & $17, V$ & 0 & $17, V$ & 0 & $\cdot, \cdot$ & . & ما بين 10-10 سنه & $r$ \\
\hline
\end{tabular}

\section{أولاً: بيانات أساسية:}

جدول (1): توزيع الأطفال بلا مأوى بالمؤسسات الرعاية في المناطق الثعبية الاكثر فقرا طبقا

$$
\text { * دال عند مستوى معنوية } 0 \text {.,. }
$$


يحدد الجدول السابق: توزيع الاطفال بلا ماوي بالمؤسسات الرعاية في المناطق الثعبية

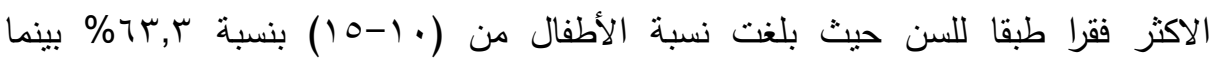
انخفضت نسبة الأطفال دون سن العاشرة بنسبة •r\% وكذلك نسبة الأطفال من (1 الفأكثر)

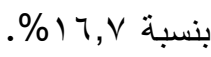

توجد فروق جوهرية ذات دلالة معنوية بين توزيع الاطفال بلا مأوى بالمؤسسات الرعاية

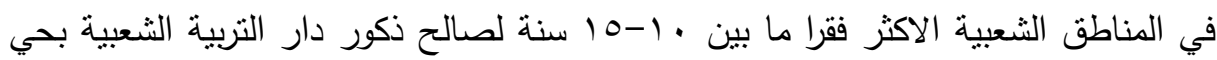

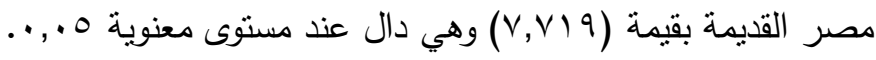

جدول (ץ): نوزيع الاطفال بلا ماوي بالمؤسسات الرعاية في المناطق الثعبية الاكثر فقرا طبقا

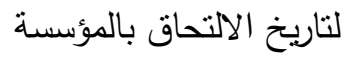

\begin{tabular}{|c|c|c|c|c|c|c|c|c|}
\hline \multirow[t]{2}{*}{ كا' } & \multicolumn{2}{|c|}{ الاجمالي } & \multicolumn{2}{|c|}{ بعاية الفتيات } & \multicolumn{2}{|c|}{ الثكور دارية } & النوع & \\
\hline & $\%$ & العدد & $\%$ & العدد & $\%$ & العدد & بالمؤسسة & \\
\hline \multirow{4}{*}{$r, q .0$} & $\overline{r T, r}$ & $\bar{v}$ & $7, \mathrm{Y}$ & $\bar{Y}$ & $17, V$ & 0 & آلقل من عام & 1 \\
\hline & $\varepsilon \cdot, \cdot$ & IT & $\overline{Y T, r}$ & $\mathrm{~V}$ & $17, V$ & 0 & من ( - 7 سنوات & $\bar{r}$ \\
\hline & $r r, r$ & V & $17, V$ & 0 & $7, V$ & $r$ & 7-، ا سنوات & $\Gamma$ \\
\hline & r, & $\varepsilon$ & $r, r$ & 1 & $1 \cdot, \cdot$ & r & من ·1 - 1 | سنة & $\varepsilon$ \\
\hline
\end{tabular}

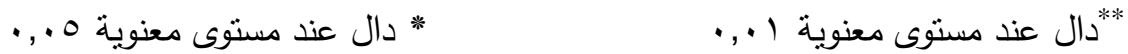

يحدد الجدول السابق: توزيع الاطفال بلا مأوى بالمؤسسات الرعاية في المناطق الثعبية

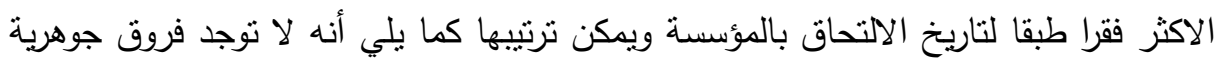

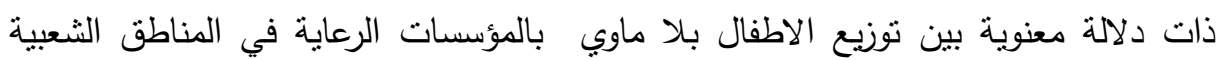

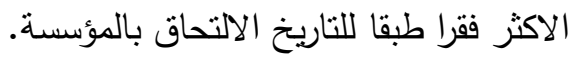

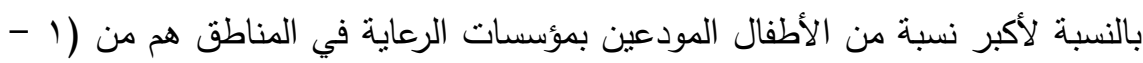

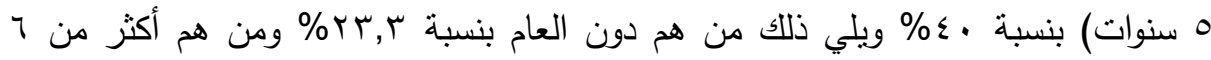

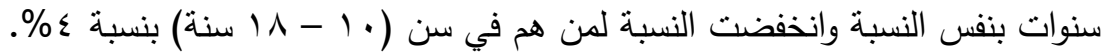


جدول (ץ): توزيع الاطفال بلا مأوى بالمؤسسات الرعاية في المناطق الثعبية الاكثر فقرا طبقا لأسباب الالتحاق بالمؤسسة الأسي

\begin{tabular}{|c|c|c|c|c|c|c|c|c|}
\hline \multirow[t]{2}{*}{ r } & \multicolumn{2}{|c|}{ | الاجمالي } & \multicolumn{2}{|c|}{ النتاث } & \multicolumn{2}{|c|}{ القكور دار التربية } & \multirow[b]{2}{*}{ سبب الالتحاق } & \multirow[t]{2}{*}{ ? } \\
\hline & $\%$ & |العدد & $\%$ & العدد & $\%$ & العدد & & \\
\hline $1, r 95$ & $r, \mathrm{~V}$ & 11 & $1 r, r$ & $\varepsilon$ & $r, r$ & v & الهروب إلى الثارع & 1 \\
\hline$\cdots$ & $r \uparrow, V$ & $\wedge$ & $1 r, r$ & $\varepsilon$ & $1 r, r$ & $\varepsilon$ & مجهول النسب & r \\
\hline $1,7 V \mathrm{~V}$ & $r r, r$ & $v$ & $17, V$ & 0 & $7, \mathrm{~V}$ & $r$ & قسوة الوالدين & $r$ \\
\hline $1,7 V V$ & $r r, r$ & $v$ & $17, V$ & 0 & $7, \mathrm{~V}$ & $r$ & الطلاق & $\varepsilon$ \\
\hline., 174 & $17, V$ & 0 & $7, V$ & $r$ & $1 \cdot, \cdot$ & $r$ & وفاة الوالدين & 0 \\
\hline r.17. & $17, V$ & 0 & $\begin{array}{rr}r, r \\
\end{array}$ & 1 & $1 T, r$ & $\varepsilon$ & سوء الحالة الاقتصادية & 7 \\
\hline$\cdot, \cdots$ & $1 r, r$ & $\varepsilon$ & $T, V$ & $r$ & $7, \mathrm{~V}$ & $r$ & قسوة الأب & $\mathrm{v}$ \\
\hline$r v \cdot$. & $1 \cdot, \cdot$ & $r$ & $7, V$ & $r$ & $r, r$ & 1 & وفاة الأم & ᄉ \\
\hline מחזיז & $1 \cdot, \cdot$ & $r$ & - & - & $1 \cdot, \cdot$ & $r$ & كبر حجم العائلة & 9 \\
\hline$r, 1 \leqslant r$ & $7, V$ & $r$ & $T, V$ & $r$ & - & - & وفاة الأب & 1. \\
\hline$r, 1 \leqslant r$ & $7, Y$ & $r$ & $7, V$ & $r$ & - & - & ق قسوة الأم & 11 \\
\hline
\end{tabular}

يحدد الجدول السابق: نوزيع الاطفال بلا ماوي بمؤسسات الرعاية في المناطق الثعبية الاكثر

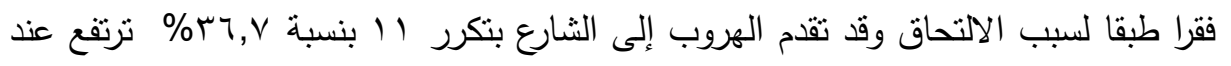
ذكور دار التربية الشعبية بحي مصر القديمة.

كما لوحظ أن نسبة الأطفال الذين التحقوا بالمؤسسات في الترتيب التالي أن الأطفال

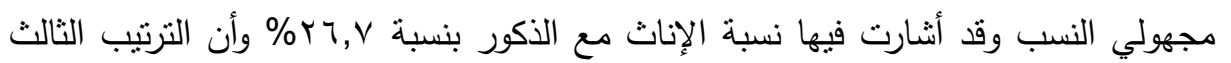

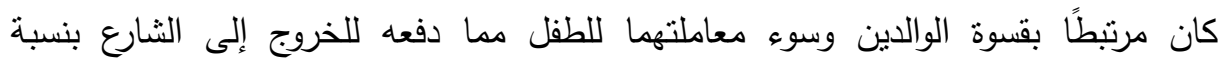
rr,r\% وقد نراجعت نسبة العوامل الأخرى إلى الطلاق بين الوالدين وكذلك وفاة الوالدين وسوء الأحوال الاقتصادية وغير ذلك من العوامل التي اتضحت من الجدول السابق.

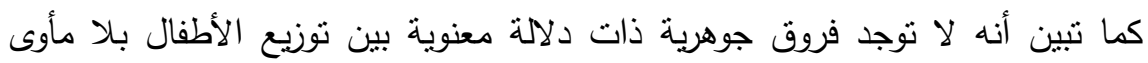
بالمؤسسات الرعاية في المناطق الثعبية الاكثر فقرا طبقا للسبب الالتحاق. 
جدول (ء): توزيع الاطفال بلا ماوي بالمؤسسات الرعاية في المناطق الشعبية الاكثر فقرا طبقا

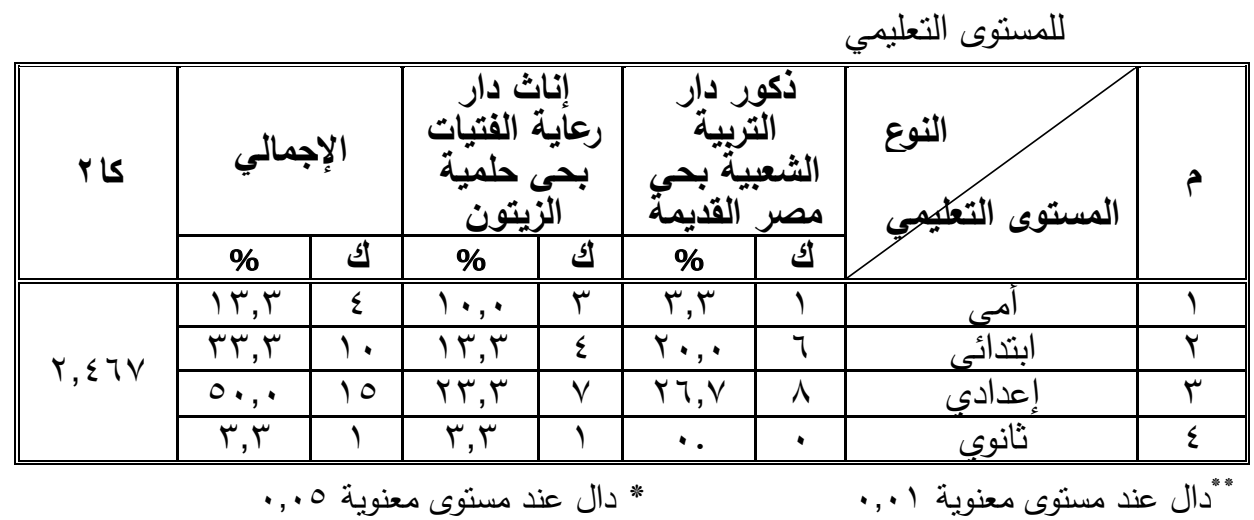

يحدد الجدول السابق:الحالة التعليمية الاطفال بلا ماوي بالمؤسسات الرعاية في المناطق

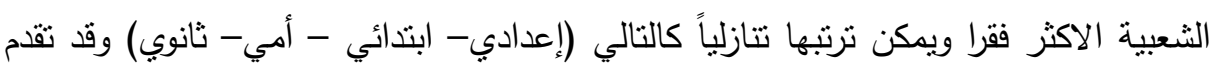
إعدادي بتكرر 10 بنسبة .,.0 \% ارتفعت عند ذكور دار التربية الثعبية بحي مصر القديمة

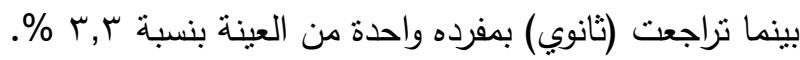

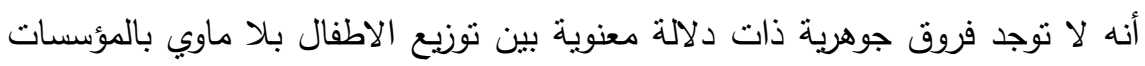
الرعاية في المناطق الثعبية الاكثر فقرا طبقا للمستوى التعليمي.

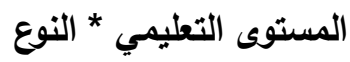

جدول (•): توزيع الاطفال بلا مأوي بالمؤسسات الرعاية في المناطق الثعبية الاكثر فقرا طبقا للمستوى القراءة والكتابة

\begin{tabular}{|c|c|c|c|c|c|c|c|c|}
\hline \multirow[t]{2}{*}{ كا' } & \multicolumn{2}{|c|}{ الإجمالي } & \multicolumn{2}{|c|}{ بحاية الفتيات داثي } & \multicolumn{2}{|c|}{ 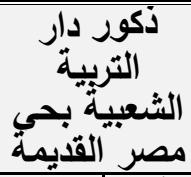 } & \multirow{2}{*}{ القراءة والكتابةم } & \\
\hline & $\%$ & ك & $\%$ & 5 & $\%$ & 5 & & \\
\hline \multirow{3}{*}{$1, r q r$} & $07, V$ & IV & $\overline{r \cdot, \cdot}$ & 9 & YY,V & 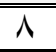 & يقراً ويكتب & 1 \\
\hline & $\Gamma, \Gamma$ & $T$ & $\Gamma, \Gamma$ & $T$ & $\because$ & 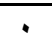 & يقراً ولا يكتب & $r$ \\
\hline & $\varepsilon \cdot, \cdot$ & $T r$ & $17, V$ & 0 & $T r, r$ & $\mathrm{~V}$ & لا يقرا ولا يكتب & $\Gamma$ \\
\hline
\end{tabular}

* دال عند مستوى معنوية 0 ., . *دال عند مستوى معنوية ل •,. 
يحدد الجدول السابق: توزيع الاطفال بلا ماوي بالمؤسسات الرعاية في المناطق الشعبية الاكثر

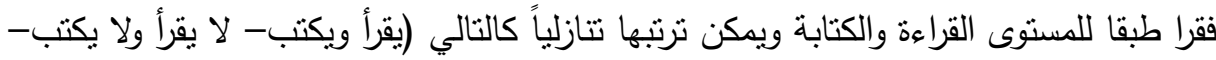

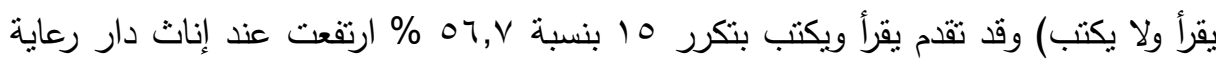

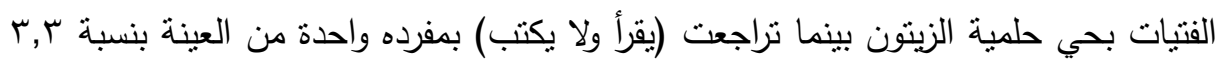
. \%

أنه لا توجد فروق جوهرية ذات دلالة معنوية بين توزيع الاطفال بلا مأوي بالمؤسسات الرعاية في المناطق الثعبية الاكثر فقرا طبقا للمستوى القراءة والكتابة.

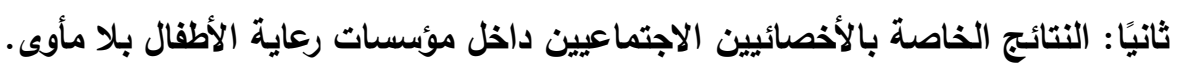
وصف الخصائص لعينة من المشرفات والأخصائي الاجتماعي داخل المؤسسة: جدول (1) سن المبحوثات من الأخصائيين الاجتماعيين

\begin{tabular}{|c|c|c|c|}
\hline$\%$ & العدد & الســن & م \\
\hline YY,Y & $r$ & أقل من ·r & 1 \\
\hline$\varepsilon \leqslant, \varepsilon$ & $\varepsilon$ & ס & $r$ \\
\hline$r, Y$ & $r$ & $-\varepsilon$. & $r$ \\
\hline $11, r$ & 1 & •0 فأكثر & $\varepsilon$ \\
\hline$\% 1 \ldots$ & 9 & المجموع & \\
\hline
\end{tabular}

بلغ المتوسط الحسابي لأعمار الأخصائيات الاجتماعيات ب, اء (واحد وأربعون) عامًا

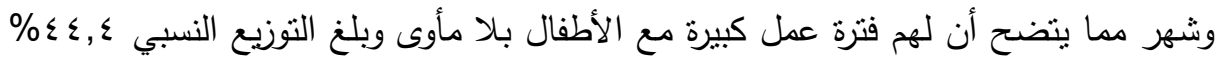

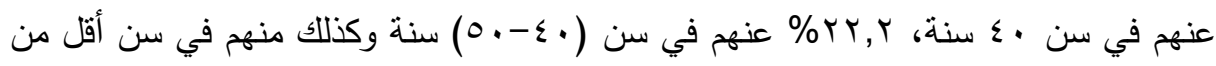

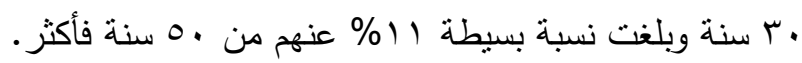

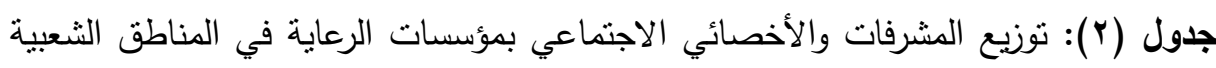

\begin{tabular}{|c|c|c|c|}
\hline \multicolumn{2}{|c|}{$q=\dot{q}$} & \multicolumn{2}{|c|}{ الأكثر فقرا طبقا للحالة الاجتماعية } \\
\hline$\%$ & العدد & الحالة الاجتماعية & م \\
\hline$r \mu, r$ & r & آنسة & 1 \\
\hline $77, V$ & 7 & متزوجة & $\bar{r}$ \\
\hline$\% 1 \ldots$ & 9 & المجموع & \\
\hline
\end{tabular}




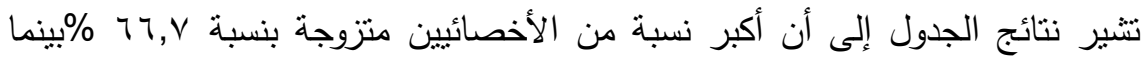

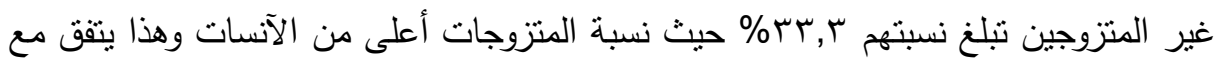

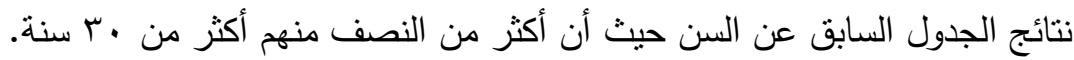

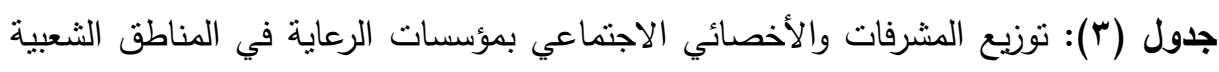

\begin{tabular}{|c|c|c|c|}
\hline ن & \multicolumn{2}{|c|}{ الأكثر فقرا طبقا لمؤهل الخدمة الاجتماعية } & \\
\hline$\%$ & ك5 & المؤهلات & 5 \\
\hline$Y Y, Y$ & $r$ & دبلوم خدمة اجتماعية & 1 \\
\hline$V \vee, \Lambda$ & $\mathrm{V}$ & بكالوريوس خدمة اجتماعية & r \\
\hline$\% 1 \ldots$ & 9 & المجموع & \\
\hline
\end{tabular}

تتثير النتائج الخاصة بالبحث إن معظمه حاصل على بكالوريوس الخدمة الاجتماعية

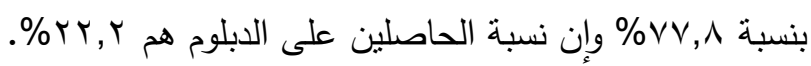
جلول (؛ ): توزيع المشرفات والأخصائي الاجتماعي بالمؤسسات الرعاية في المناطق الثعبية $q=\dot{ }$

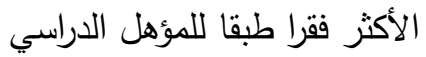

\begin{tabular}{|c|c|c|c|}
\hline$\%$ & العدد & المؤهل الدراسي & s \\
\hline YY,Y & $r$ & متوسط & 1 \\
\hline$\varepsilon \varepsilon, \varepsilon$ & $\varepsilon$ & عالىي & $r$ \\
\hline r r r & $r$ & دراسات عليا (ماجستير -دكتوراه) & $r$ \\
\hline$\% 1 \ldots$ & 9 & المجموع & \\
\hline
\end{tabular}

تشير نتائج الجدول أن أكبر نسبة من الاخصائيين حاصلين على مؤهل عالى بنسبة

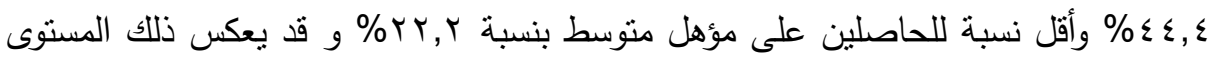
التعليمى المناسب هم أكثر قدرة على التعامل مع هذه الفئة وأكثر معرفة ودراية بحل

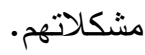
كما كانت هنالك نسبة r,rr\% من الإحصائيات يحملن دراسات عليا (ماجستير

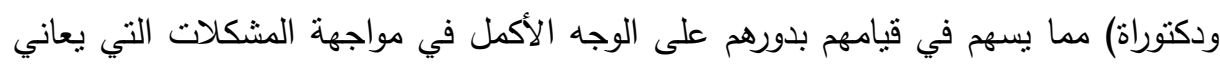

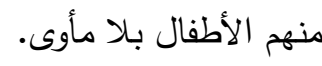


جلول (•): توزيع المشرفات والأخصائي الاجتماعي بالمؤسسات الرعاية في المناطق الثعبية

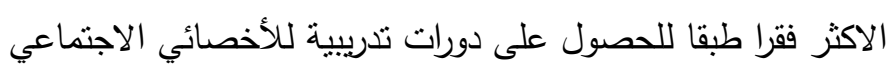

\begin{tabular}{|c|c|c|c|}
\hline$\%$ & ك5 & حصول على دورات تدريبية للأخصائي الاجتماعي & م \\
\hline$\wedge \wedge, 9$ & $\Lambda$ & نعت & 1 \\
\hline 11,1 & 1 & $y$ & $r$ \\
\hline$\% 1 \ldots$ & 9 & المجموع & \\
\hline
\end{tabular}

تثبير نتائج الجدول أن الحاصلين على دورات تدريبية نسبة ^^,9 \% بينما الذين لم

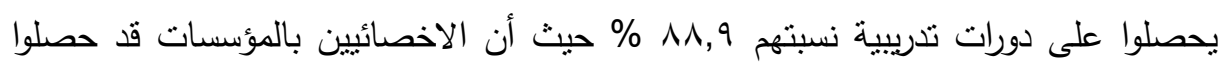

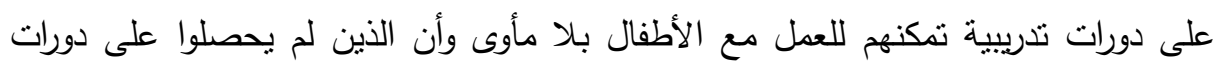
تدريبية عدد (1) أخصائي اجتماعي بنسبة (1,1) (1) وهم لم يحصلوا على دورات تدريبية لتؤهلهم للعمل مع هذه الفئة.

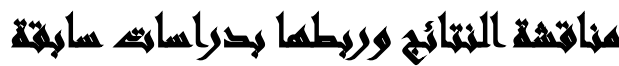

أكدت نتائج البحث وعلاقاتها بالدراسات السابقة: 1-أن هناك قصور في خدمات وبرامج الرعاية الاجتماعية المقدمة لأطفال بلا مأوى في

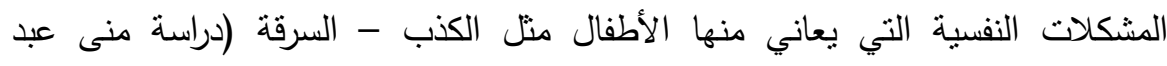

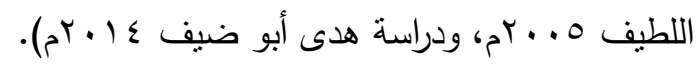

r- أن هناك نقص في الأخصائيين الاجتماعيين بالمؤسسات مع كثرة عدد الأطفال الأيتام

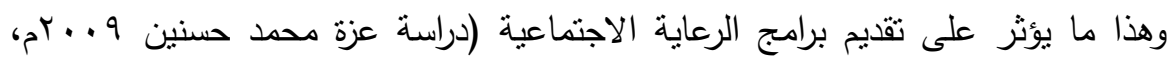

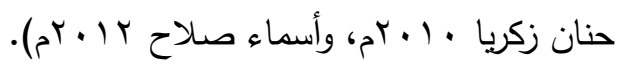

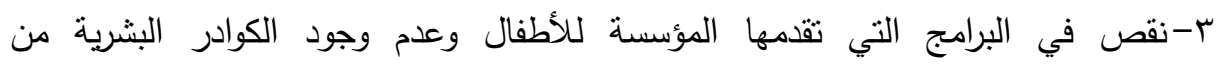
الأخصائيين الاجتماعيين مما يؤثر على تقديم الخدمات، (دراسة محمود سعد محمود 
ع- هنالك قصور في بعض الخدمات المقدمة للأطفال المودعين بالمؤسسات وعدم إثباعهم

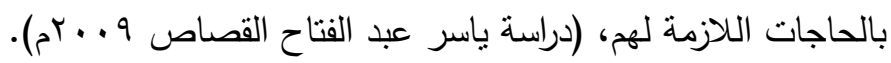

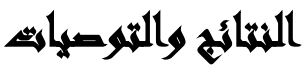

1- ضرورة تكثيف برامج التوعية بمؤسسات الرعاية الاجتماعية لأطفال بلا مأوى حول برامج الرعاية الصحية والتعليمية والاجتماعية والنفسية. r- أن يكون لدور مؤسسات الرعاية دور أكثر فاعلية من كونها مكان لإيواء الأطفال. وأن يكون أهداف المؤسسة مركزة على تعديل السلوكيات السلبية لديهم.

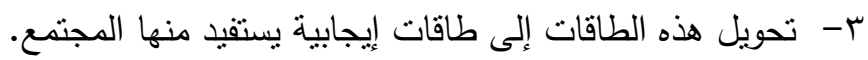
ع - ضبط الثارع من قبل الجهات الأمنية حتى لا يكون هناك مكان للطفل في الثشارع. ه- تفعيل قانون حماية الطفل والحفاظ على حقوقه داخل المؤسسة. 7- المشرفات والأخصائيين الاجتماعيين ضرورة حصولهم على على مؤهلات عليا بالخدمة الاجنماعية والأفضل دراسات عليا في مجال رعاية الطفل. - ضرورة حصول المشرفين والأخصائيين الاجتماعيين على برامج توعية ودورات تدريبية من قبل المجلس القومي للطفولة والأمومة من قبل وزارة التضامن الاجتماعي.

\section{المراجي}

أحمد أبو زيد(9V0 ( ) البناء الاجتماعي مدخل لدراسة المجتمع. الهيئة المصرية للكتاب

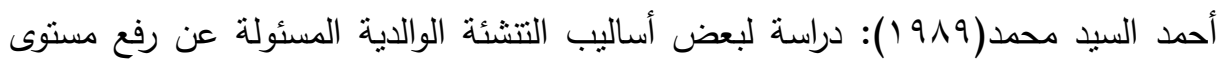
الطموح في ضوء بعض المتغيرات الديموجرافية، ماجستير غير منشورة، كلية

الآداب، جامعة طنطا

أحمد زلط( . . †): معجم الطفولة (مفاهيم لغوية ومصطلحية)، دار الوفاء لدنيا الطباعة والنشر والتوزيع، الإسكندرية

أحمد عزت راجح(910 (1): أصول علم النفس، دار المعارف، القاهرة أحمد عكاشة(ب99 (19)): الطب النفسي المعاصر، مكنبة الأنجلو المصرية، القاهرة 
أحمد غنيمي مهناوي محمد(ب99(1): الدور التربوي لمؤسسات الرعاية الاجتماعية، دراسة للمؤسسات الإيوائية في محافظة القليوبية، دكتوراه غير منشورة، كلية التربية، جامعة الزقازيق، فرع بنها

أحمد محمد عليق(1991 (19): مدخل في إدارة المؤسسات الاجتماعية، طلبة الخدمة الاجتماعية،

$$
\text { جامعة حلوان }
$$

إسماعيل مصطفى سالم(9 (9 () دراسة مقارنة بين أسلوب الرعاية المؤسسية والأسر البديلة

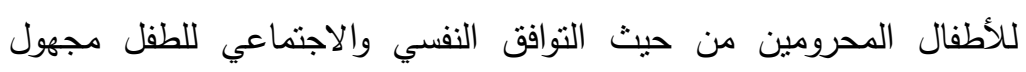

النسب، رسالة ماجسنير غير منشورة، كلية الخدمة الاجتماعية، جامعة حلوان

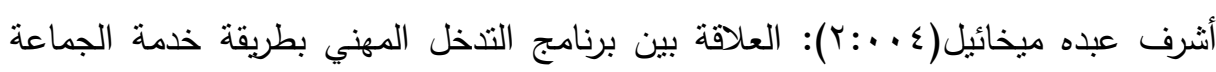

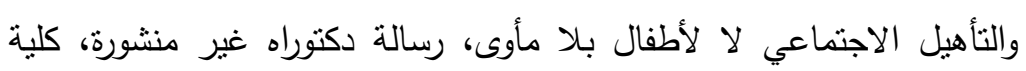

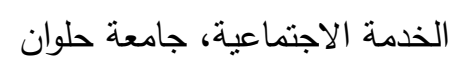

إلهام عبد العزيز الساعي(919 (1)): اختيار مدى فاعلية نموذج حل للمشكنة في طريقة خدمة الفرد لزيادة التوافق النفسي والاجتماعي لدى الأطفال المحرومين من الرعاية

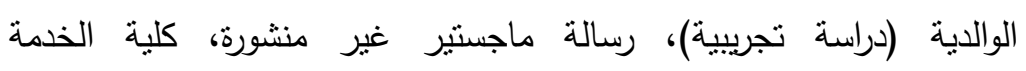
الاجتماعية جامعة القاهرة فرع الفيوم

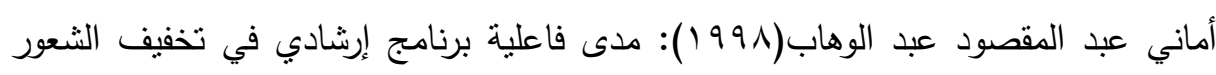

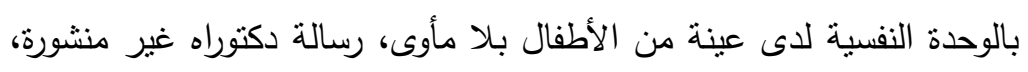

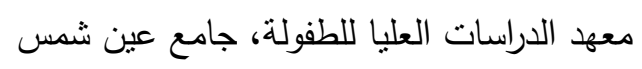
إملي صادق ميخائيل(·99 (1): دراسة مقارنة للقلق لاى الأطفال في الأسرة البديلة والأسرة

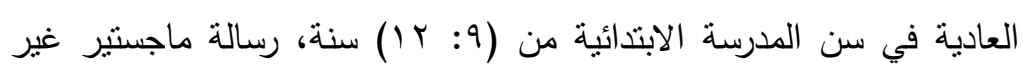

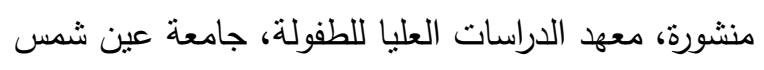

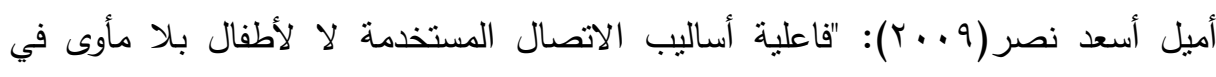

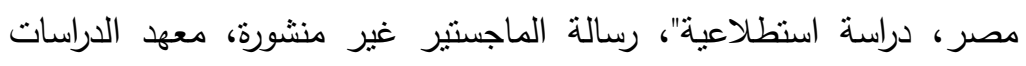

$$
\text { العليا للطفولة، جامعة عين شمس درسلة }
$$


أنسى محمد أحمد القاسم (919 (19): النمو الاجتماعي والانفعالي لأطفال الملاجئ في مراحله الطفولة المبكرة، دراسة مقارنة، ماجستير غير منشورة، كلية الآداب، جامعة

إيمان عبد الحميد القماح(ب/91(): دراسة إكلينيكية عن أثز الحرمان من الوالدين على البناء

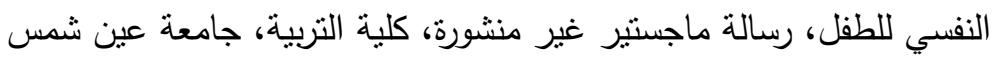

إيمان عبد العزيز عبد الوهاب: تأثير البرنامج الترويحي المقترح على تعديل سلوك الأطفال بلا

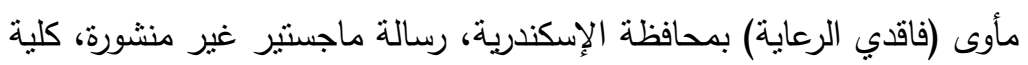
الآداب، جامعة الإسكندرية.

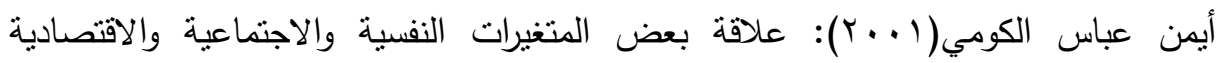

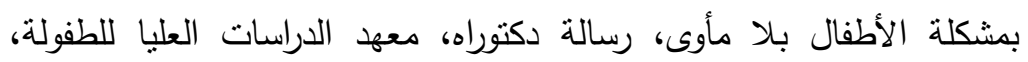

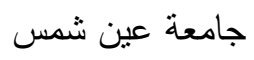

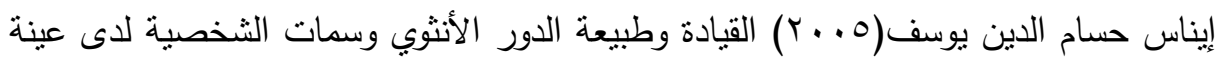

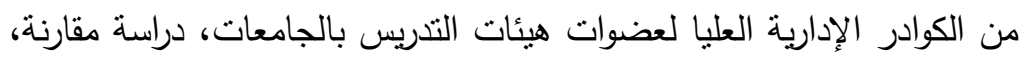

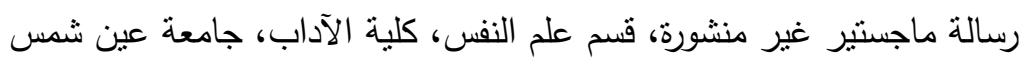

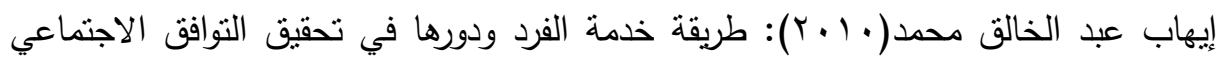
للأطفال بلا مأوى نحو نموذج علاجي مقترح، رسالة دكتوراه غير منشورة، جامعة حلوان بتصرف: علي علي التمامي: استخدام المدخل المعرفي السلوكي من منظور طريقة العمل مع

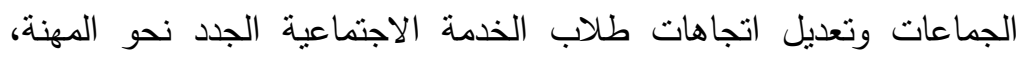

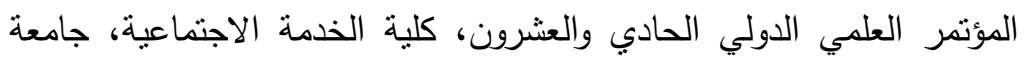
حلوان، 1 . . بأم.

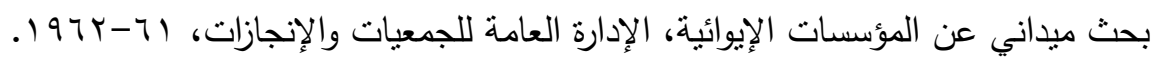

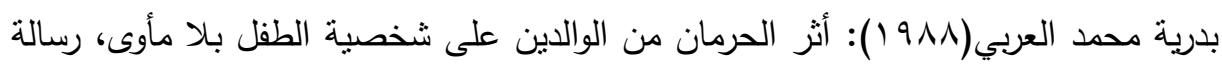

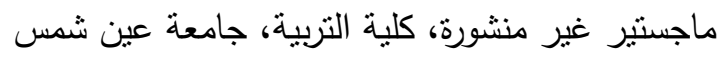

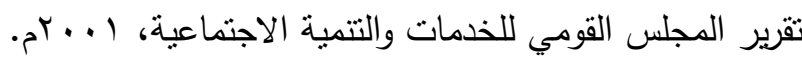




$$
\begin{aligned}
& \text { جمال حمزة: الأطفال بلا مأوى، بحث منشور بمجلة الخدمة الاجتماعية، المعه العالي }
\end{aligned}
$$

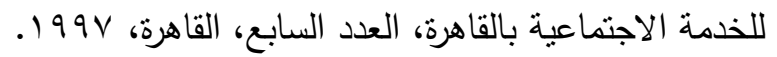

$$
\begin{aligned}
& \text { رفاعي محمد رفاعي: الإدارة بين مفهوم الرئاسة ومفهوم القيادة، دراسة تطبيقية، المجلة العربية }
\end{aligned}
$$

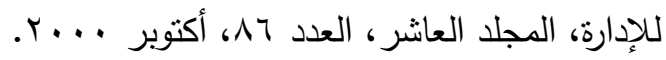

$$
\begin{aligned}
& \text { عزة شرارة: القيادة النسائية والإبداع، مجلة دراسات الوحدة العربية، ديوان العرب، ديسمبر لهورئ } \\
& \text {. T... }
\end{aligned}
$$

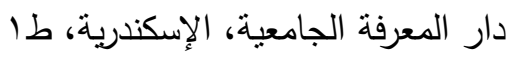

$$
\begin{aligned}
& \text { مصرية، رسالة ماجستير، قسم الاجتماع كلية الآداب، جامعة عين شمس، }
\end{aligned}
$$

Analstasi, A., Psychological Testing, New York, MacMillan, 2001.

Anderson R., A Dictionary of Management Terms, Estover MacDonald and Evans LTD., 2004.

Gore, M.S., Social work and social work education, Asia Publishing Hause, N.Y., 1965.

Howel, D., Statistical Methods for Psychology. Belmont, CA: Duxhary Press, 2002.

Linda Burrows and Robert Munday, Leadership substitutes their Effective on Teacher Organizational Commitment and Job, Satisfaction Journal of Instructional psychology, Vol. 17, No. 5, 2003.

Ryckman, R.M., Theorie of Personality Monterary, California, Books., Cole Publishing Company, 1985.

T.H. Marchell: Social Policy. Hutchinson, Co. London 1968. 


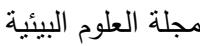

معهد الدراسات والبحوث البيئية - جامعة عين شمس لينان

\title{
THE ROLE OF THE WELFARE INSTITUTIONS IN \\ CHILDREN IN THE COMMUNITY AND CONFRONTING DEVIATION
}

\author{
Mahynaz M. Abdallah (1) Mona Mohamed K. Madhat ${ }^{(2)}$ \\ and Rashd A. abd el latif ${ }^{(3)}$ \\ 1) Institute of Environmental Studies and Research, Ain Shams \\ University 2) Faculty of Women, Ain Shams University 3) Faculty of \\ Community Service, Helwan University
}

\begin{abstract}
Homeless children is the composite of poverty and neglect the red family disintegration and violence interesting them homeless children and nursing associations have become a prerequisite. This was confirmed by interbational charters and local child care as the slide in the community vau mat be underestimated auel need to pay attention to that slot from disband them psychological and educational health social. The study problem: Childhood is considered the hope of society and the nation and the years of hope the nation Fahim hope please understand. Community who hold his mind to talk and understand the real wealth of every nation across peoples arts right on the right of their rights and work to provide appropriate conditions for them and raise them alncham sound in all aspects of community association through this category threaten the security society.

If they are not helping the kids and turning the positive community instead of children parents and are turning to a ticking time bomb threatening the community. Homeless children in who should take care of the communities and thru them community.
\end{abstract}

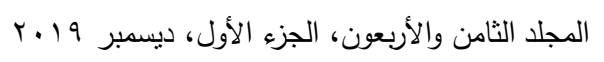

